Yavuz Hakan Ozdemir

Baris Barlas

http://dx.doi.org/10.21278/brod69302

ISSN 0007-215X

eISSN $1845-5859$

\title{
FREE SURFACE FLOW SIMULATION AROUND AN APPENDED SHIP HULL
}

UDC 629.5.015.2:629.5.018

Original scientific paper

\begin{abstract}
Summary
This study brings forward the results of previously published work of free surface flow simulation around a fast ship model. Experimental measurements and numerical simulations of a fast bare-hull ship model form are now extended to the same ship form with appendices for a wide range of Froude numbers. The governing equations are discretized by means of an unstructured finite volume mesh. The standard $k-\varepsilon$ turbulence model and Volume of Fluid Method to capture the two phase media are used. The total resistance, due to wave and wake fields of the ship model with appendages and the resistance of the appendages alone are calculated numerically, and compared with the experiments. The experiments and computations were performed for 11 different Froude numbers between 0.103 and 0.322 . For Froude numbers up to 0.25 , numerical simulations found to be quite in agreement with the experiments. It has been found that appendages increase the total drag mainly by increasing the pressure resistance, and the effect of the appendages becomes more important as the flow speed gets higher.
\end{abstract}

Key words: $\quad$ Computational Fluid Dynamics; Experiment; Turbulent free surface flows; Appendages, $k$-Eturbulence model.

\section{Introduction}

In naval architecture, advances in computational facilities have allowed scientists to use numerical simulations for effective design and optimization of hull geometry. Computational Fluid Dynamics (CFD) has advanced quickly in recent years and has become as one of the most important methods which plays crucial role in ship building industries. CFD methods are useful in analyzing flow problems in resistance estimation. While towing tank tests provide better absolute accuracy, CFD techniques can give practical results that are comparable to the towing tank test results with relatively less effort both in cost and time. While viscous flow methods give more accurate results in terms of drag than potential flow methods, potential theory to compute the free surface flow around the ship has been very much in use in recent years (see for instance [1-4]). 
With the advent of the faster computers, researchers began studying flow around ship hulls with solving Reynolds-Averaged Navier-Stokes (RANS) equations and used the results in ship design. Subramanian and Vijayakumar [5] used the RANS based simulation for minimizing wake at propeller plane. This work examined the utility of CFD in the analysis of flow in the case of full aft beam vessels having characteristic cut stern shape to facilitate propeller aperture. The study demonstrated new avenues for applications of CFD in the early design stages. In the work of Celik [6], effect of the wake-equalizing duct on the propulsion performance of a chemical tanker was investigated by using RANS based simulation. Kouh et al. [7] studied scale effect on ship form factor for different hull geometries. In their study, form factor was predicted only based on double model calculation, in which influence of the wave making resistance was ignored. Park et al. [8] investigated different skeg geometries using RANS equations. Free surface effect was not taken into account by all these studies.

The following RANS approaches were applied with success for the free surface simulations around ship: Senocak and Iaccarino [9] simulated the turbulent flow around the DTMB 5415 model with free surface and they demonstrated the feasibility of such a simulation. Bucan et al. [10] made a study using both experimental and RANS based numerical solution around a tanker hull at model scale. Results of two numerical simulations performed at design and ballast loading conditions were presented. Zwart et al. [11] described an accurate, efficient algorithm for solving free surface flows around ship hull. The accuracy of the simulation was demonstrated first on Wigley hull. More detailed testing on the DTMB 5415 hull under a variety of conditions also showed good accuracy. Ahmed and Guedes Soares [12] gave a method for simulation of viscous and potential flows around a VLCC hull form. The results compared well with the available experimental data. Various works were performed on the flow around ship hull with a free surface, reviews on the subject can be found in Wackers et al. [13], and Xing et al. [14]. Sridhar et al. [15] studied friction resistance of a ship, Kandasamy et al. [16] investigated RANS solutions for a high speed catamaran, Pranzitelli et al., Tezdogan et al., Ozdemir et al., and Farkas et al. [17-20] have investigated the total drag around ship hulls.

Additionally, CFD is widely used for optimization of the hull form: Szelangiewicz and Abramowski [21] used the CFD code for influence of ship hull form modification on ship resistance and propulsion characteristics. Mahmood and Huang [22] made a study optimizing the bulbous bow. Duy et al. [23] used CFD for the optimal design for a stern shape of a hull. Muscari et al. [24] investigated hull-propeller-rudder interactions phenomena for twin-screw ships. Other studies using CFD codes are Bhushan et al., Gaggero et al., and Kim et al. [2527].

The appendages can be responsible for an appreciable amount of the total ship resistance. The main appendages of the fast ship considered in this study are the twin shafting and shaft brackets. Normally, separate towing tank tests of a model with and without appendages are used to estimate the appendages resistance. The difference between the twomeasured resistances should give the appendages drag. In the present study, CFD and Experimental Fluid Dynamics (EFD) are used to analyze the ship resistance problem of the M 367 fast ship with appendages. Ozdemir et al. [28] reported numerical and experimental results of the bare hull of the fast ship considered here. The fast ship hull form and its appendages were developed by Sener [29]. The model experiments were conducted at Istanbul Technical University Ata Nutku Ship Model Testing Laboratory. The next sections of this paper provides details about the geometry, experimental setup, governing equations, boundary conditions, mesh system, computations, validation, and conclusions. 


\section{Geometry and experimental setup}

This study investigates a fast ship hull with appendages advancing in calm water with a free surface at different speeds. The ship hull is developed by Sener [29]. A detailed discussion of experimental setup is provided in Ozdemir et al [28]. The model is constructed on 1/36 scale with the model number M 367. The ship model was made of wood. Figure 2 shows the constructed model photographs of the M367 with and without appendages. Different CAD render of the hull geometry is depicted in Figure 3. Studs applied at the bow and on the rudder to stimulate turbulent flow (Figure 4). During the model resistance analysis, the air resistance was omitted and the ship the model is tested in free calm water condition free to dynamic trim and sinkage. Table 1 gives the model ship and main ship particulars. Table 2 gives the towing tank test conditions.
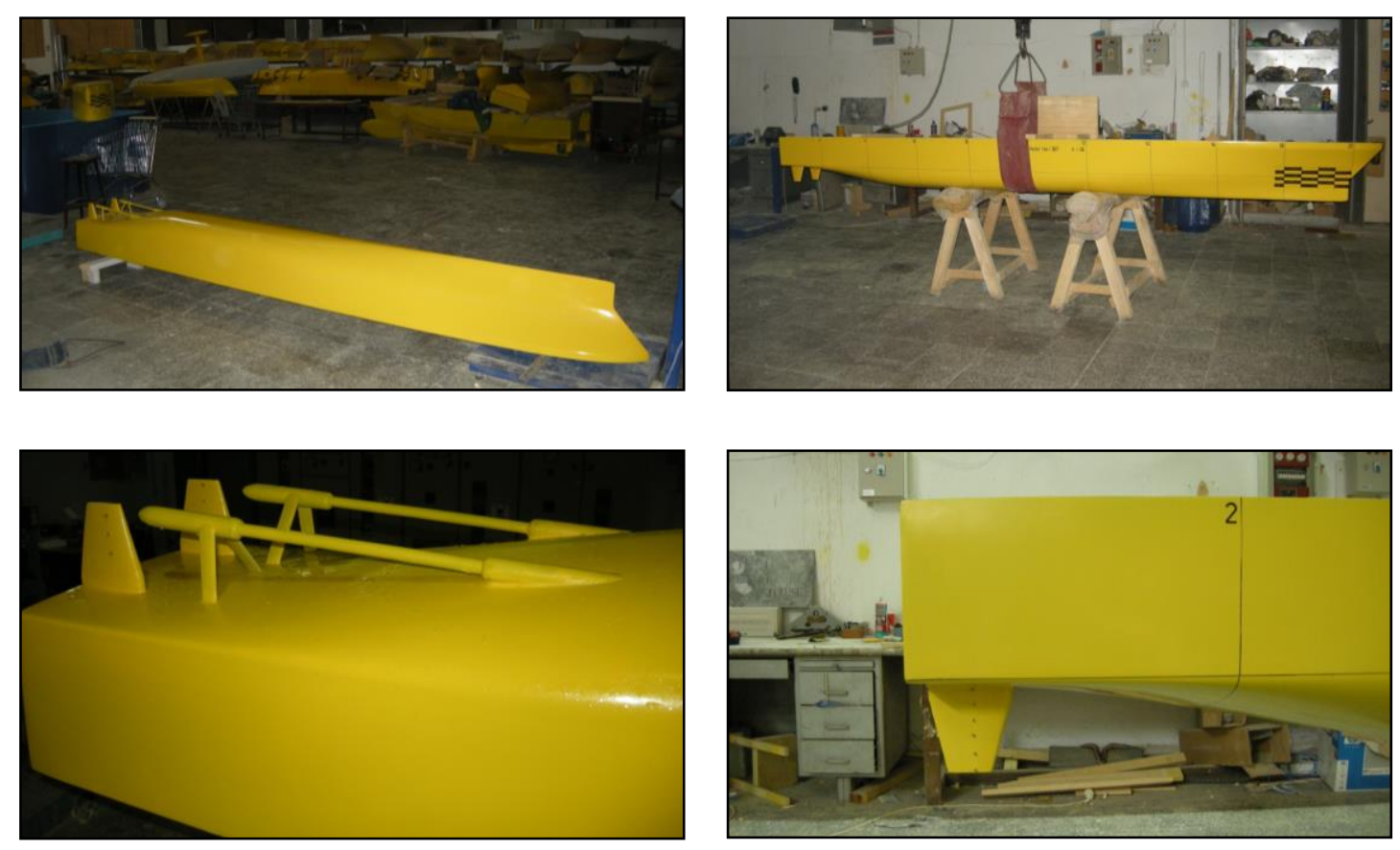

Fig. 2 Different views of the M367 ship model with and without appendages 

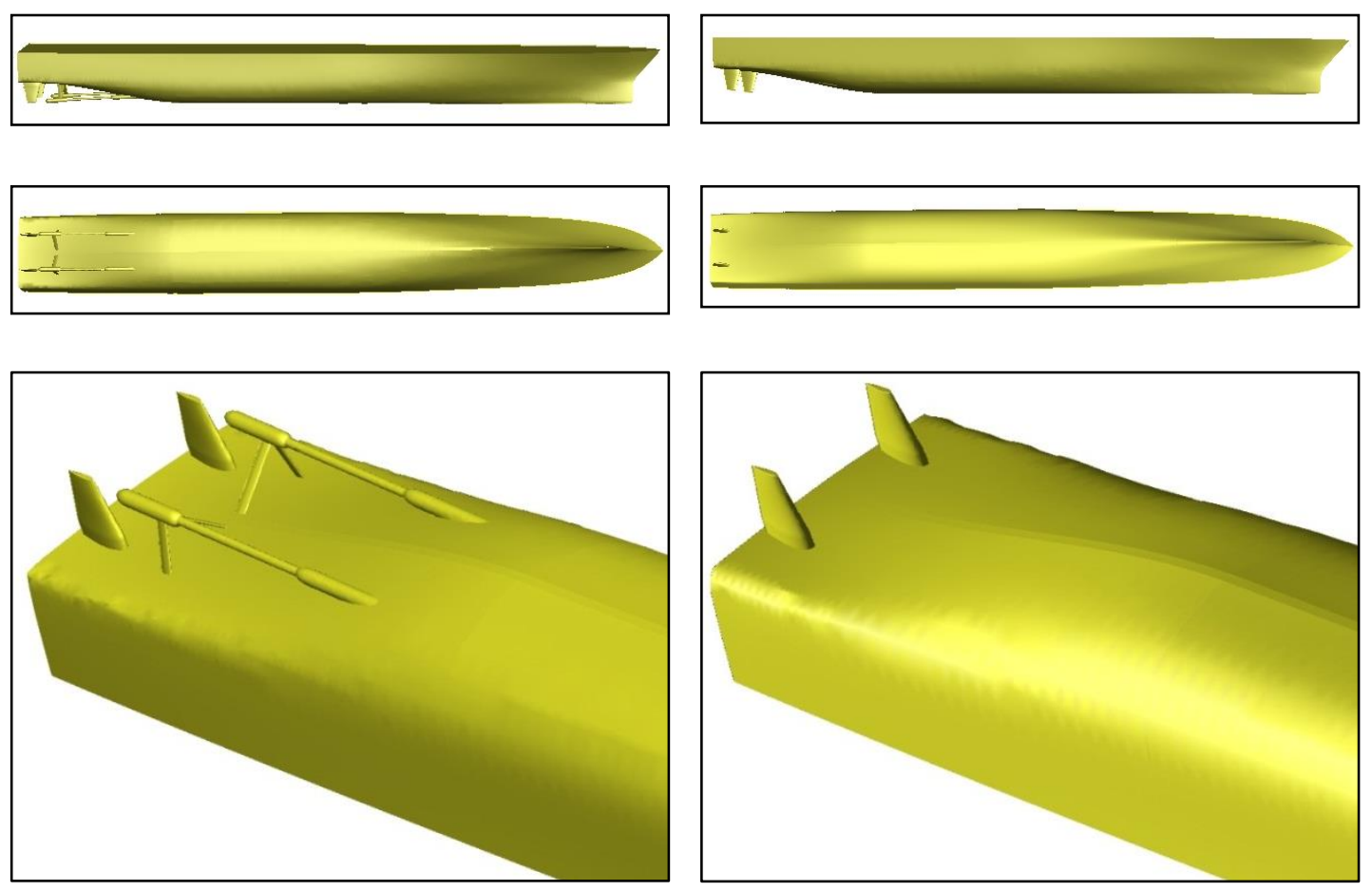

Fig. 3 CAD render of M 367 ship model with and without appendages

Table 1 Main particulars of the main ship and the model ship

\begin{tabular}{|l|l|l|}
\hline & Ship Prototype & Model M367 \\
\hline Length on the waterline $\mathrm{L}_{\mathrm{WL}}(\mathrm{m})$ & 139.07 & 3.863 \\
\hline Length between perpendiculars $\mathrm{L}_{\mathrm{BP}}(\mathrm{m})$ & 139 & 3.861 \\
\hline Moulded breadth $\mathrm{B}(\mathrm{m})$ & 18.20 & 0.506 \\
\hline Moulded depth to upper deck $\mathrm{D}(\mathrm{m})$ & 11.20 & 0.31 \\
\hline Design draft $\mathrm{T}(\mathrm{m})$ & 5.05 & 0.140 \\
\hline Block coefficient $\mathrm{C}_{\mathrm{B}}$ & 0.489 & 0.489 \\
\hline Midship coefficient $\mathrm{C}_{\mathrm{M}}$ & 0.810 & 0.810 \\
\hline Prismatic coefficient $\mathrm{C}_{\mathrm{P}}$ & 0.605 & 0.605 \\
\hline Waterline coefficient $\mathrm{C}_{\mathrm{WP}}$ & 0.793 & 0.793 \\
\hline Design speed $\mathrm{V}_{\mathrm{S}}$ & $18 \mathrm{kts}$ & $1.538 \mathrm{~m} / \mathrm{s}$ \\
\hline Displacement volume $\nabla\left(\mathrm{m}^{3}\right)$ & 5768.24 & 0.124 \\
\hline Wetted surface area $\mathrm{A}_{\mathrm{WS}}\left(\mathrm{m}^{2}\right)$ & 2550.30 & 1.968 \\
\hline Total rudder area $\mathrm{A}_{\mathrm{R}}\left(\mathrm{m}^{2}\right)$ & 56.66 & 0.043 \\
\hline Total appendages area $\mathrm{A}_{\mathrm{A}}\left(\mathrm{m}^{2}\right)$ & 116.36 & 0.089 \\
\hline
\end{tabular}


Table 2 Towing tank test conditions

\begin{tabular}{|c|c|}
\hline Test conditions & Value \\
\hline Temperature $\left({ }^{\circ} \mathrm{C}\right)$ & 16 \\
\hline Density $\left(\frac{\mathrm{kg}}{\mathrm{m}^{3}}\right)$ & 998.9 \\
\hline Gravitational acceleration $\left(\frac{\mathrm{m}}{\mathrm{s}^{2}}\right)$ & 9.803 \\
\hline Kinematic viscosity $\left(\frac{\mathrm{m}^{2}}{\mathrm{~s}}\right)$ & $1.113 \mathrm{E}-06$ \\
\hline
\end{tabular}
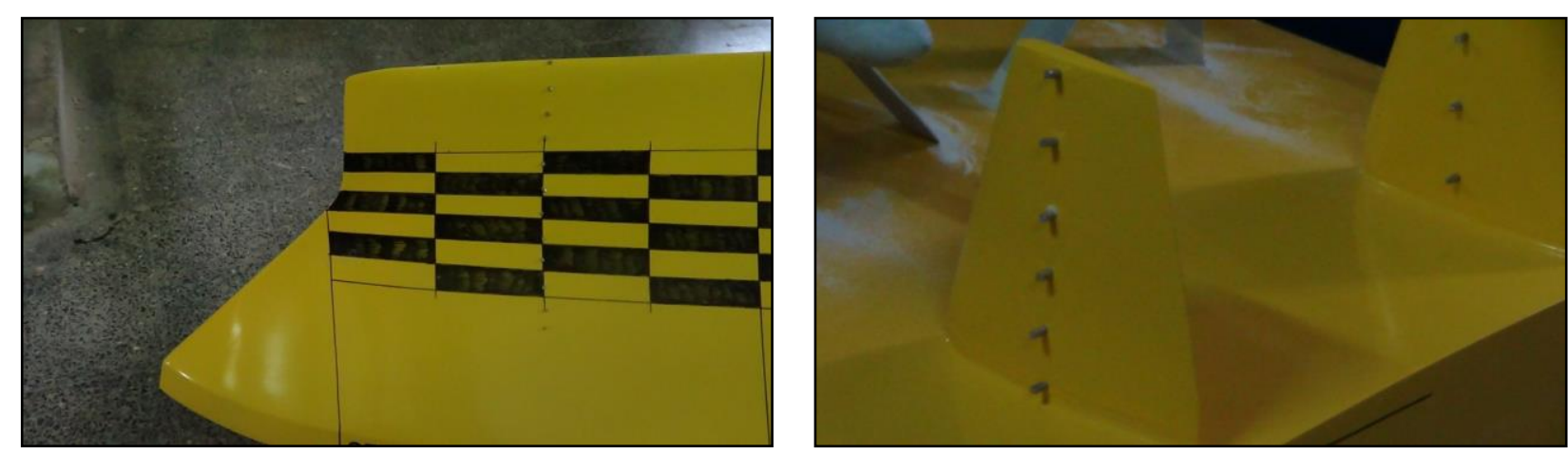

Fig. 4 Turbulent studs on ship bow and rudder

\section{Mathematical formulation}

\subsection{Governing equations}

The unsteady RANS equations for an incompressible, three-dimensional flow are continuity equation:

$$
\frac{\partial U_{i}}{\partial x_{i}}=0
$$

Momentum equation:

$$
\frac{\partial U_{i}}{\partial t}+\frac{\partial\left(U_{i} U_{j}\right)}{\partial x_{j}}=-\frac{1}{\rho} \frac{\partial P}{\partial x_{i}}+\frac{\partial}{\partial x_{j}}\left[v\left(\frac{\partial U_{i}}{\partial x_{j}}+\frac{\partial U_{j}}{\partial x_{i}}\right)\right]-\frac{\partial \overline{u_{i}^{\prime} u_{j}^{\prime}}}{\partial x_{j}}
$$

Where $x_{\mathrm{i}}$ is the spatial coordinate, $t$ is the time, $U_{\mathrm{i}}$ is the mean velocity, $u_{\mathrm{i}}^{\prime}$ is the fluctuating velocity, $P$ is the mean pressure, $\rho$ is the fluid density and $v$ is the kinematic viscosity. The Reynolds stress tensor is modelled by the Boussinesq approximation. The eddy viscosity based standard $\mathrm{k}-\boldsymbol{\varepsilon}$ turbulence closure model is used. A detailed description of the mathematical model is presented in $[28,30]$. The pressure and velocity coupling problem is solved by using the SIMPLE algorithm where the velocity field are first solved using a presumed pressure. Then pressure and velocity fields are corrected with the calculated values of pressure and velocity [31]. Calculations are made in unstructured finite volume mesh for half of the model hull symmetric to its centerline. 


\subsection{Boundary conditions}

The computational domain is limited by different boundary conditions. In the computations the following boundary conditions are used: external (inlet and outflow), symmetry, solid wall and free surface. For near wall flow regions wall function is used, where the viscous layer is not resolved. The dimensions of the computational domain are selected by the recommendations of ITTC procedures in order to prevent wave reflections. Therefore, the computational domain ranges from $-3.0 \mathrm{~L}_{\mathrm{BP}}<\mathrm{x}<3.0 \mathrm{~L}_{\mathrm{BP}}, 0.0<\mathrm{y}<2.0 \mathrm{~L}_{\mathrm{BP}}$ and $-1.0 \mathrm{~L}_{\mathrm{BP}}<\mathrm{z}$ $<1.0 \mathrm{LBP}$, where half of the body is modelled to decrease the computational domain size and time. The ship axis is located along the $\mathrm{x}$-axis with the bow located at $\mathrm{x}=\mathrm{L}_{\mathrm{BP}}$ and the stern at $x=0$. The still water level lies at $\mathrm{z}=0$. The dimensions of the computational domain satisfy the well-known ITTC procedure. Detailed information about the principles of computational domain dimensions' selection strategy can be found in [18] and [19]. Also, a detailed description of the boundary conditions is given in [28]. The general view of the computational domain and the boundary conditions are shown in Figure 5.

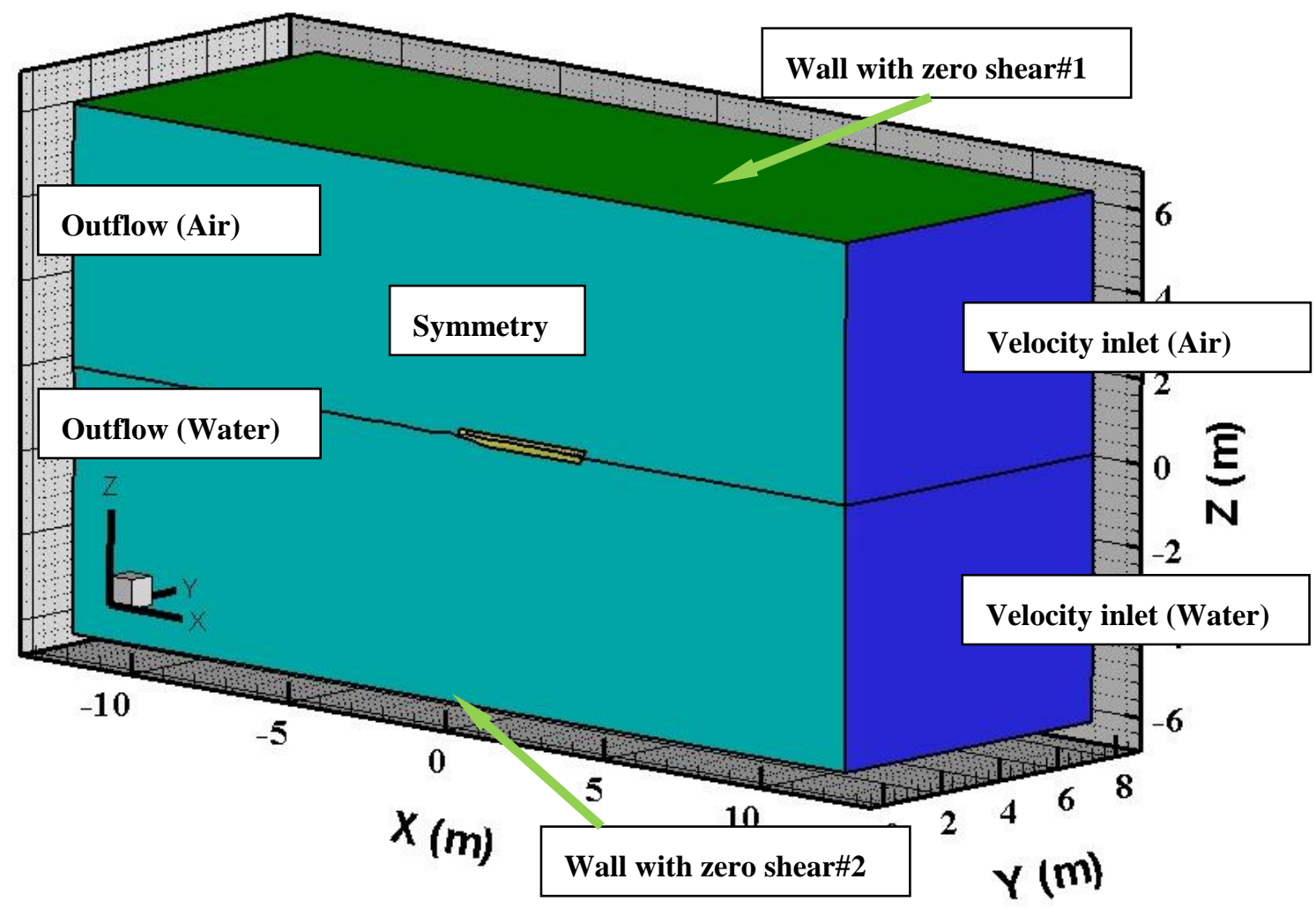

Fig. 5 The general view of the domain and boundary conditions

\subsection{Mesh structure}

In this study, an unstructured hexahedral mesh is used. Hexahedral mesh with minimum cell skewness permits flexibility, especially in local mesh refinement for free surface waves. The numerical mesh created for this study is given in Figure 6. In general, grid points are grouped around the hull, its appendages and calm water plane in the vertical range of expected wave heights to provide adequate resolution at the free surface interface. For the 
viscous flow simulation, 4 layers of prismatic cells are applied around the hull and its appendages. The stretching factor of prism layers is 1.5. Local mesh refinement is accomplished by means of volumetric controls of predefined geometrical shapes and the total number of the grid points for the mesh structure is shown in Table 3.

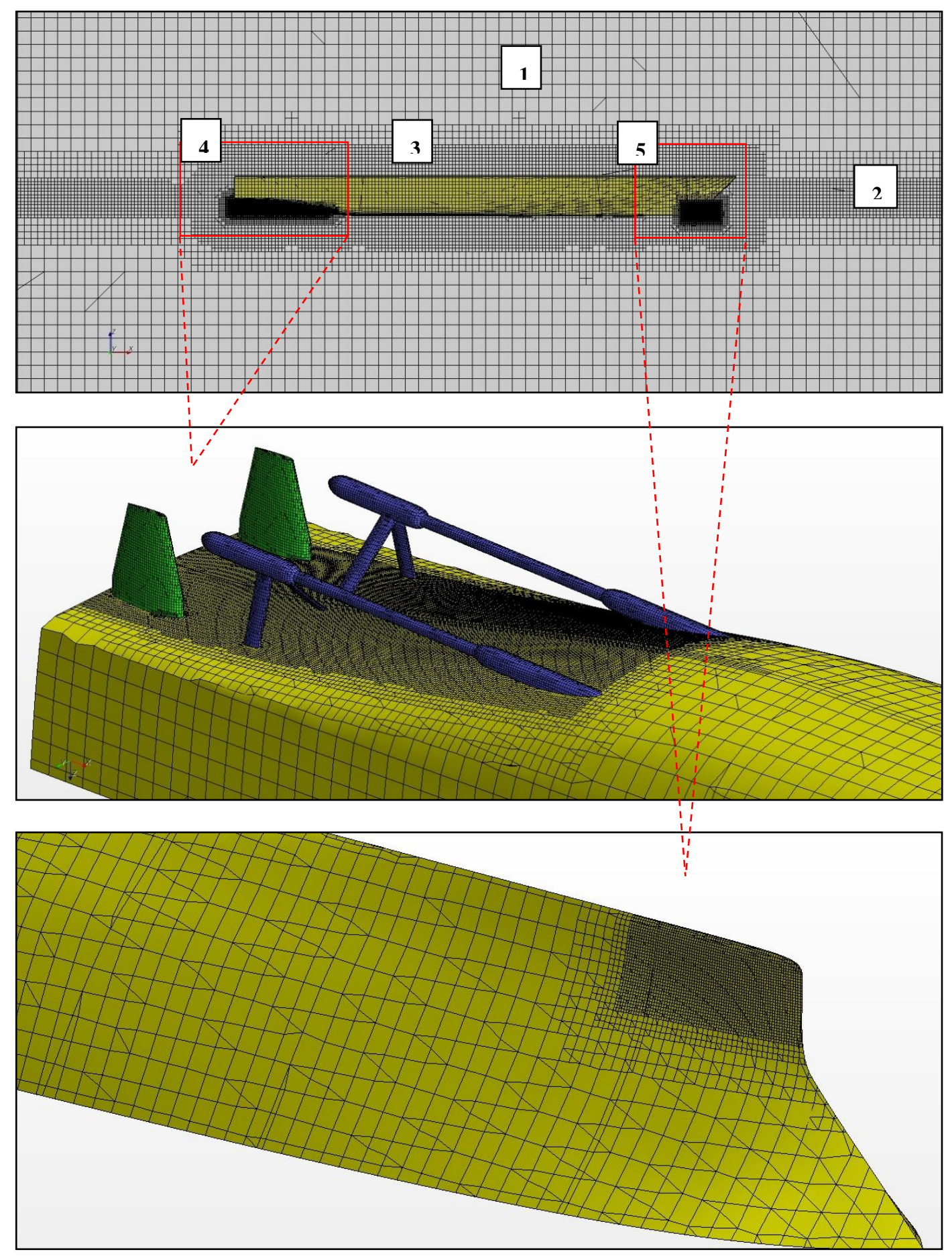

Fig. 6 The mesh structure for the M367 hull with appendages, close-up view 
Table 3 Mesh resolution

\begin{tabular}{|c|c|c|}
\hline Block \# & Block Name & Medium mesh \\
\hline 1 & Control volume & $0.085 \mathrm{~L}$ \\
\hline 2 & Free surface & $0.01 \mathrm{~L}$ \\
\hline 3 & Near ship & $0.01 \mathrm{~L}$ \\
\hline 4 & Ship's aft-end & $0.002 \mathrm{~L}$ \\
\hline 5 & Ship's fore-head & $0.002 \mathrm{~L}$ \\
\hline \multicolumn{2}{|l}{ Total number of generated cells } & $1,494,643$ \\
\hline
\end{tabular}

Because of the computational restrictions, the turbulent studs could not be used in the mesh system. The construction of a good mesh is crucial to the success of a CFD analysis. For reliable and dependable drag force results in the simulations of flow around hulls, the researcher should spent hefty time in mesh designing. Mesh refinement through adaption is also very important where needed to resolve the flow field around the hull. The mesh dependency study was carried out by Ozdemir et al. [28] for $\mathrm{Fr}=0.201$. As the computations using the same approach with the similar mesh resolution with the bare hull configuration given in [28], a mesh dependency study has not been performed for the appended hull. Medium mesh is quite good to calculate the total resistance.

\section{Results and discussions}

Model experiment and numerical simulation of appended hull is investigated similar test condition and Froude numbers with the bare hull for calculate the effect of the appendages on the resistance. Simulations presented in this study were performed for 11 selected test conditions. The main motivation is to examine the effect of appendages on the ship resistance. Convergence of the iterative solution is mediated by the normalized residual of free surface elevation is less than $10^{-2}$ and residuals of all the remaining variables are less than $10^{-5}$. The computations are made on an $8 \mathrm{CPU}$ workstation with $3.4 \mathrm{GHz}$, on windows Win7 system. Explanations of the numerical method can be found in [32]. The time step $\Delta t$ is chosen to be $0.01 \mathrm{~s}$ based on the ITTC CFD guideline [33].

\subsection{Resistance}

Table 4 shows the measured and computed total resistance values and the difference between computation and the experiment for given speeds for the M367 ship model with and without appendages. For bare hull, the comparison with the experimental measures is very good for Froude numbers between 0.103 and 0239. Within the given range, the maximum error is $5.90 \%$ at $\mathrm{Fr}=0.239$. The RANS computations generally predicted lower total resistance values. The model tests indicate that the computations predicted $9.44 \%$ lower total resistance at $\mathrm{Fr}=0.264,12.40 \%$ lower total resistance at $\mathrm{Fr}=0.286$ and $17.96 \%$ lower total resistance at $\mathrm{Fr}=0.322$ compared to the experiments. For the appended hull, the comparison with the experimental measures is very good for Froude numbers between 0.127 and 0.215. Within the given range, the maximum error is $6.92 \%$ at $\mathrm{Fr}=0.215$. Computed and measured total resistance for M367 model can be seen at Figure 7. Convergence history of the total resistance of appended ship is given in Figure 8. Allowing adequate time for the free surface to develop around the model and the drag force converge, the simulations are calculated for 
50 seconds. Both from Table 4 and Figure 7, mutually experimental and computational results show that the resistance of the hull with appendages is greater than the bare hull as expected. One of the reason is that increasing of the wetted surface area due to the appendages.

Table 4 Comparison between experimentally and numerically evaluated total resistance results for the model with and without appendages

\begin{tabular}{|c|c|c|c|c|c|c|c|}
\hline \multirow{3}{*}{$F r$} & \multirow{3}{*}{$V(\mathrm{~m} / \mathrm{s})$} & \multicolumn{2}{|c|}{ Experiment } & \multicolumn{2}{|c|}{$C F D$} & \multicolumn{2}{|c|}{$\begin{array}{c}\text { Difference } \\
\left|\frac{C F D-E X P}{E X P}\right| \%\end{array}$} \\
\hline & & $\begin{array}{l}\text { Bare } \\
\text { Hull }\end{array}$ & $\begin{array}{c}\text { Appended } \\
\text { Hull } \\
\end{array}$ & $\begin{array}{l}\text { Bare } \\
\text { Hull }\end{array}$ & $\begin{array}{c}\text { Appended } \\
\text { Hull }\end{array}$ & \multirow{2}{*}{$\begin{array}{l}\text { Bare } \\
\text { Hull }\end{array}$} & \multirow{2}{*}{$\begin{array}{c}\text { Appended } \\
\text { Hull }\end{array}$} \\
\hline & & $R_{T M}(N)$ & $R_{T M}(N)$ & $R_{T M}(N)$ & $R_{T M}(N)$ & & \\
\hline 0.103 & 0.634 & 1.988 & 2.088 & 1.926 & 2.432 & $3.11 \%$ & $16.48 \%$ \\
\hline 0.127 & 0.784 & 2.947 & 3.167 & 2.822 & 3.295 & $4.23 \%$ & $4.06 \%$ \\
\hline 0.149 & 0.918 & 3.913 & 4.287 & 3.879 & 4.177 & $0.88 \%$ & $2.58 \%$ \\
\hline 0.168 & 1.037 & 4.902 & 5.436 & 4.893 & 5.158 & $0.18 \%$ & $5.12 \%$ \\
\hline 0.186 & 1.143 & 5.893 & 6.519 & 5.929 & 6.137 & $0.60 \%$ & $5.86 \%$ \\
\hline 0.201 & 1.239 & 6.874 & 7.593 & 6.892 & 7.142 & $0.26 \%$ & $5.94 \%$ \\
\hline 0.215 & 1.325 & 7.845 & 8.662 & 7.900 & 8.062 & $0.71 \%$ & $6.92 \%$ \\
\hline 0.239 & 1.474 & 9.785 & 10.745 & 9.208 & 9.726 & $5.90 \%$ & $9.47 \%$ \\
\hline 0.264 & 1.628 & 12.245 & 13.270 & 11.090 & 11.946 & $9.44 \%$ & $9.97 \%$ \\
\hline 0.286 & 1.758 & 14.736 & 15.886 & 12.909 & 13.932 & $12.40 \%$ & $12.30 \%$ \\
\hline 0.322 & 1.980 & 19.650 & 21.066 & 16.123 & 17.437 & $17.96 \%$ & $17.22 \%$ \\
\hline
\end{tabular}

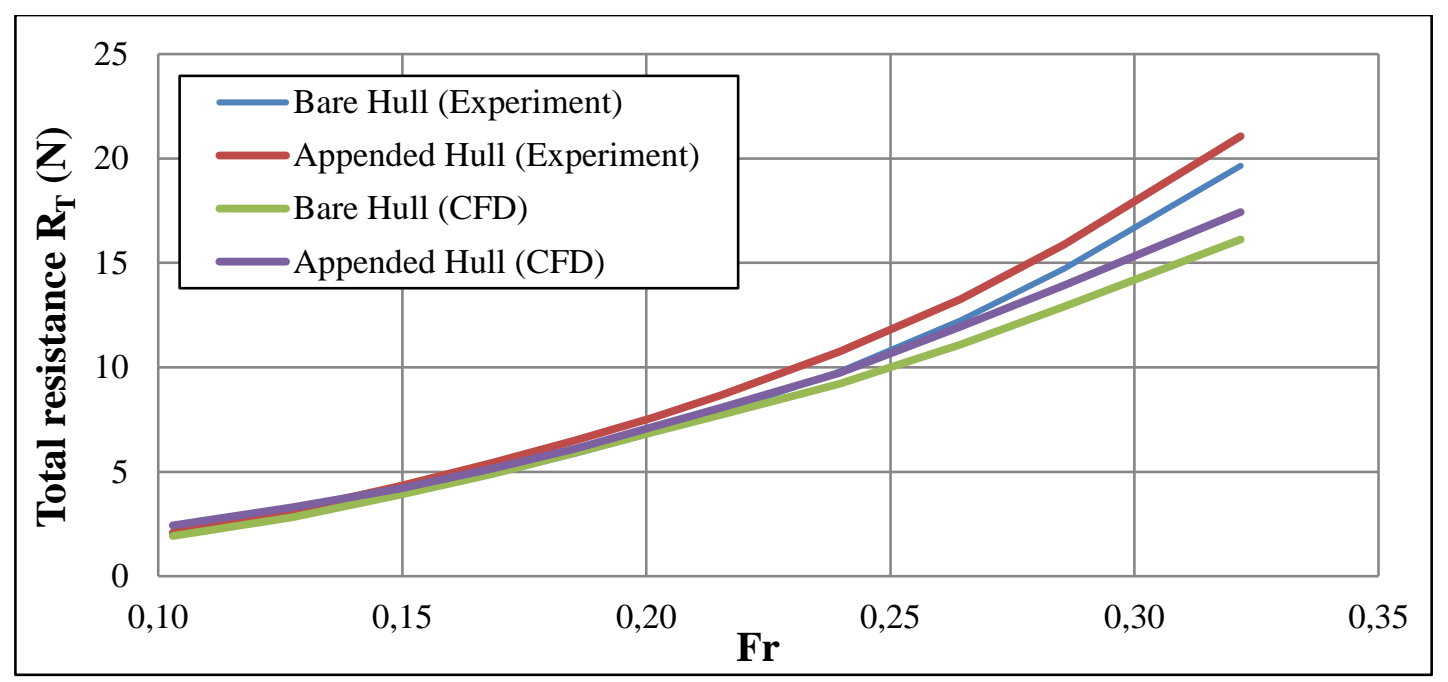

Fig. 7 Computed and measured total resistance for the model with and without appendages

Computed and measured appendages resistance is depicted in Figure 9. It can be seen that, appendages resistance alone increase with the growth in the Froude number. Comparison 
between experimental and numerical results reveal that for Froude numbers between 0.186 and 0.239, appendages resistance differences are increased. The obtained differences are believed due to the shape of the appendages, which may trigger transition from the laminar flow to the turbulent flow. On the other hand, in the experimental study, turbulence studs were used which may influence the experimental results. A faster flow will produce higher $y^{+}$ values. The precision of $y^{+}$values determines the quality of boundary layer solution, which affects the friction force. During the simulations $y^{+}$values are checked in every speed analysis. The numerically evaluated non-dimensional $\mathrm{y}^{+}$wall distance variations on the model for two different speeds are given in Figure 10. It is seen that the $y^{+}$values of the first grid points above the model hull are ranged between 30 and 120, as required.

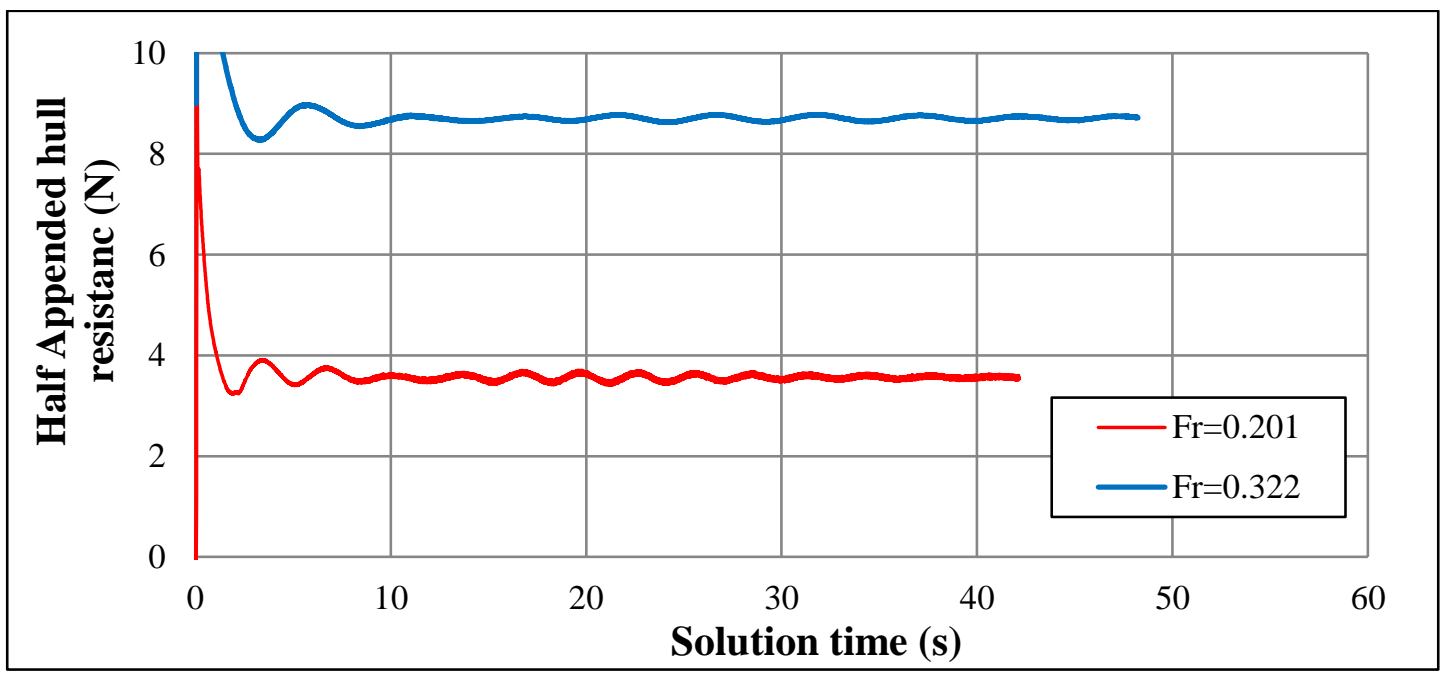

Fig. 8 Convergence history of total drag during computation for $\mathrm{Fr}=0.201$ and $\mathrm{Fr}=0.322$

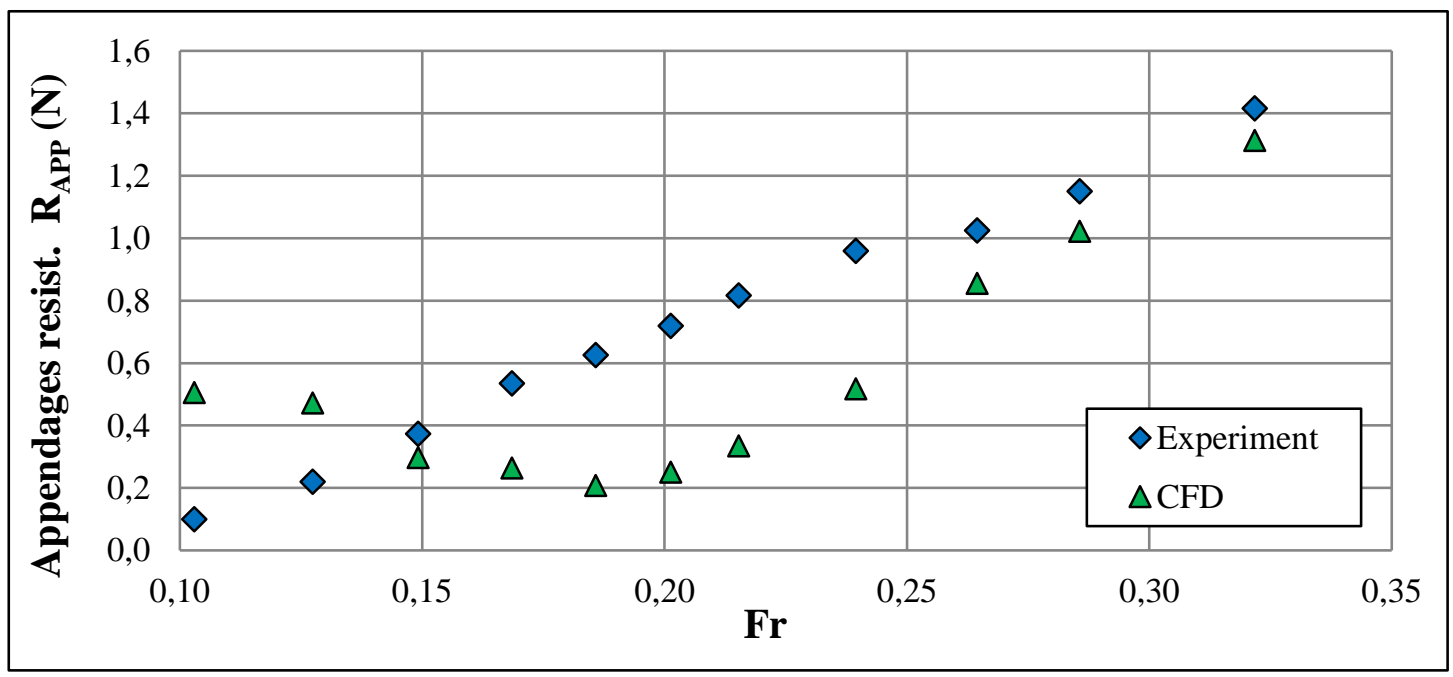

Fig. 9 Comparison of computed and measured appendages resistance

Figure 11 shows body contours of the pressure coefficient on the M367 ship model with and without appendages for two different speeds $(\mathrm{Fr}=0.215$ and $\mathrm{Fr}=0.322)$. The areas with greater pressure coefficient values have a significant contribution to pressure resistance. 

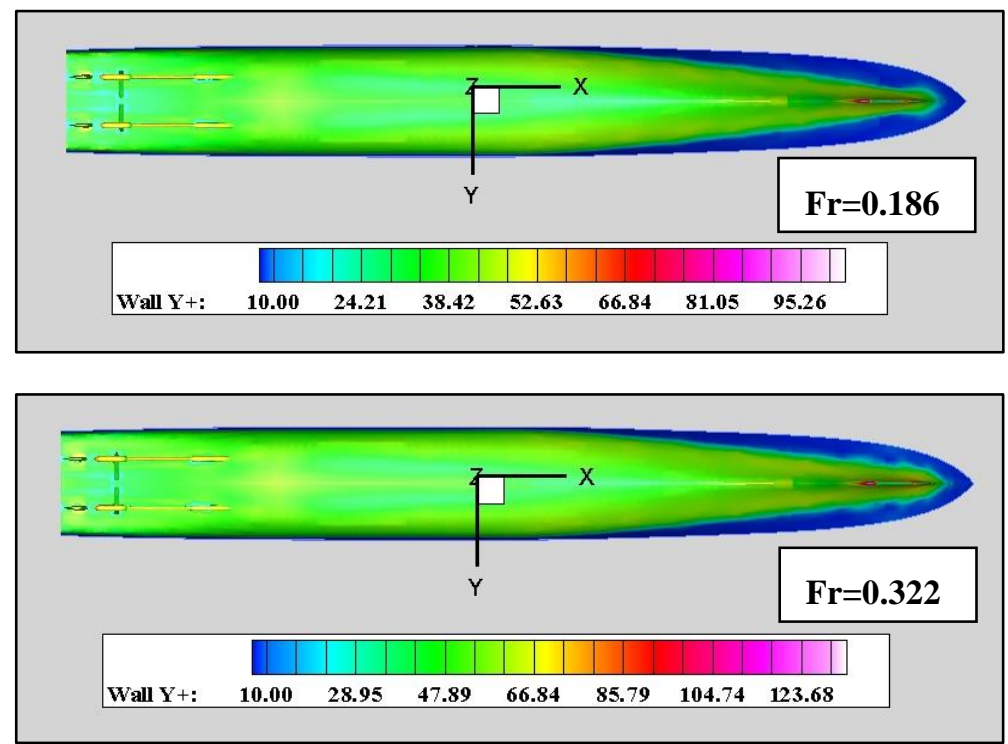

Fig. 10 Computed non-dimensional $\mathrm{y}^{+}$wall distance distribution on the model for $\mathrm{Fr}=0.186$ and $\mathrm{Fr}=0.322$

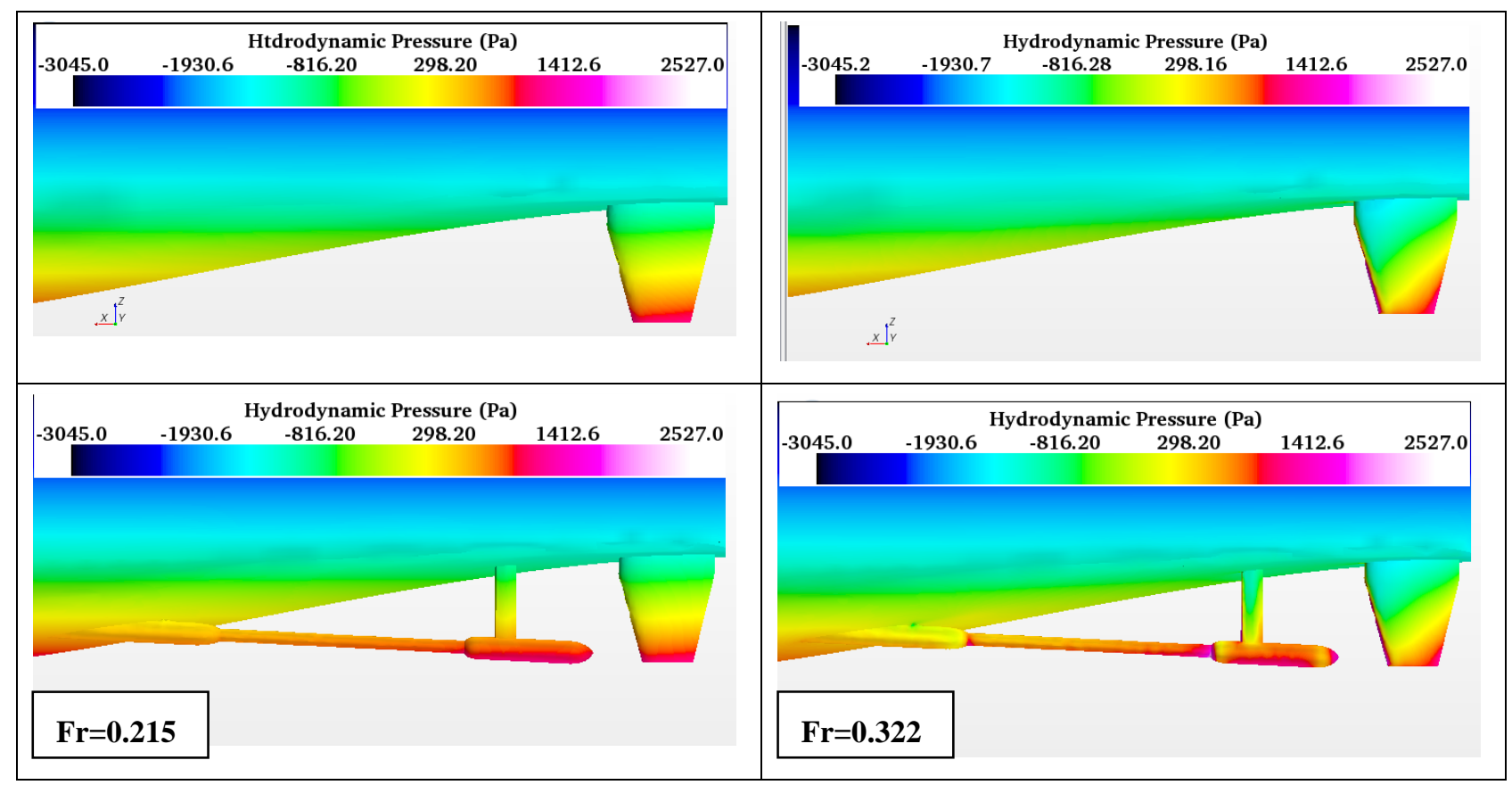

Fig. 11 Contours of pressure coefficient on the model with and without appendages for $\mathrm{Fr}=0.215$ and $\mathrm{Fr}=0.322$

\subsection{Wave field}

Concerning the numerical simulation, Figure 12 shows the wave contours of Kelvin type wave pattern around the appended hull for two different speeds ( $\mathrm{Fr}=0.215$ and $\mathrm{Fr}=0.322$ ). Figure 13 depicts, typical bow-wave and stern-wave patterns around the appended hull for two different speeds $(\mathrm{Fr}=0.215$ and $\mathrm{Fr}=0.322)$. Figure 14 provides the close-up perspective views of the computed bow-wave and stern-wave patterns and photographs around the appended model during the experiment at the same speed of $\mathrm{Fr}=0.215$. The computation shows the formation of a thin sheet of water close to the bow. At the wake field, transom separations can be seen clearly both in CFD solution and the experiment. 

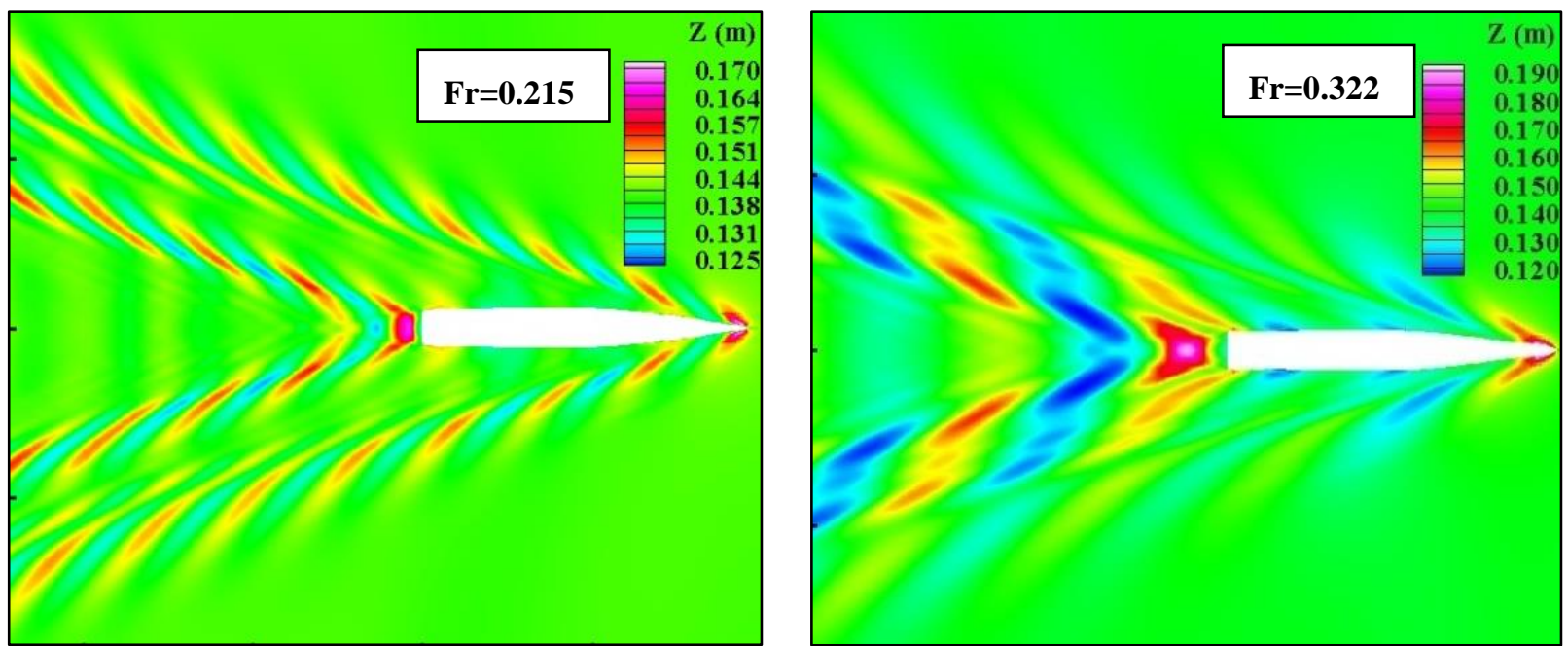

Fig. 12 Global wave pattern for the appended hull for $\mathrm{Fr}=0.215$ and $\mathrm{Fr}=0.322$
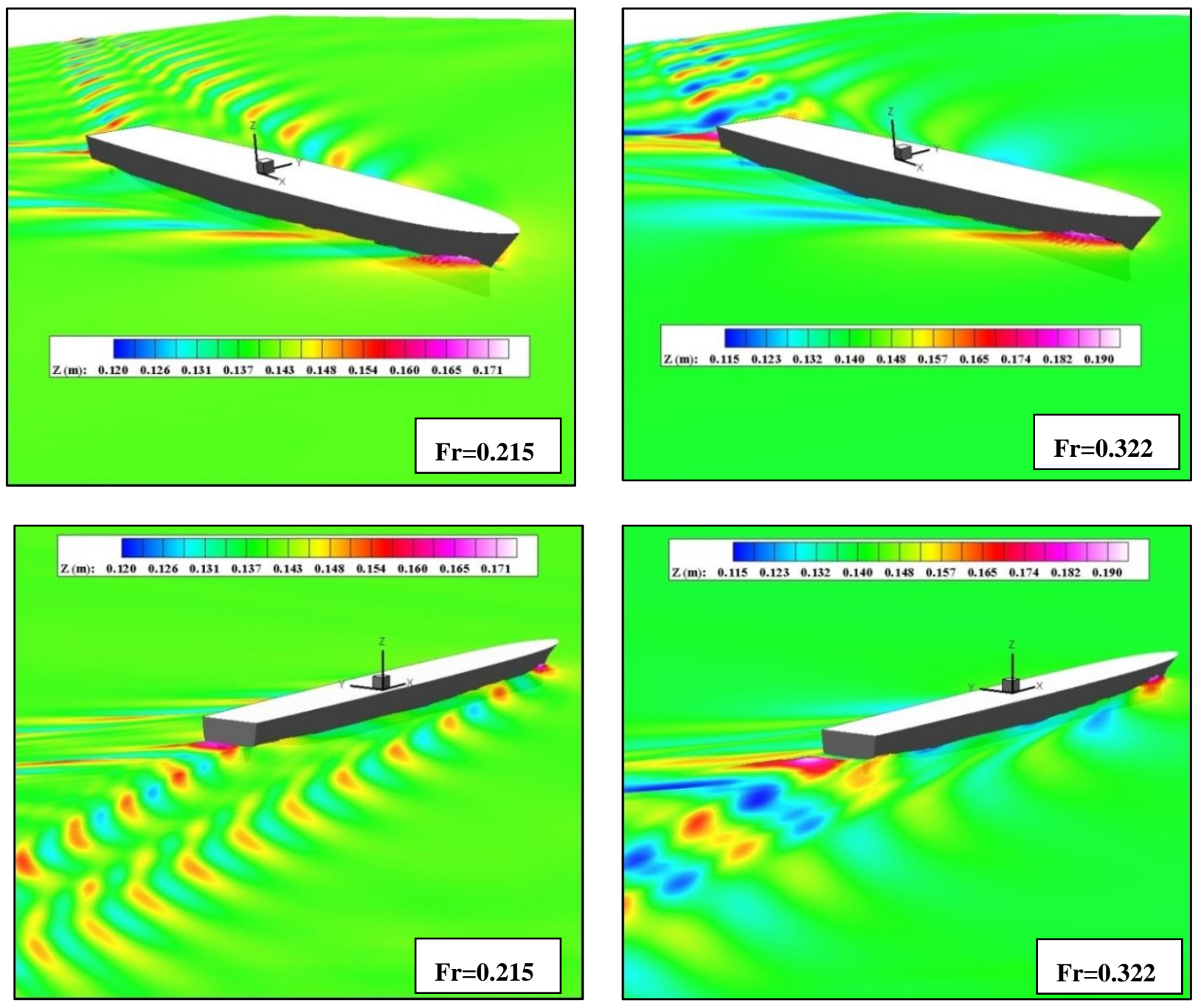

Fig. 13 Local wave patterns in bow and stern regions for the appended hull for $\mathrm{Fr}=0.215$ and $\mathrm{Fr}=0.322$ 

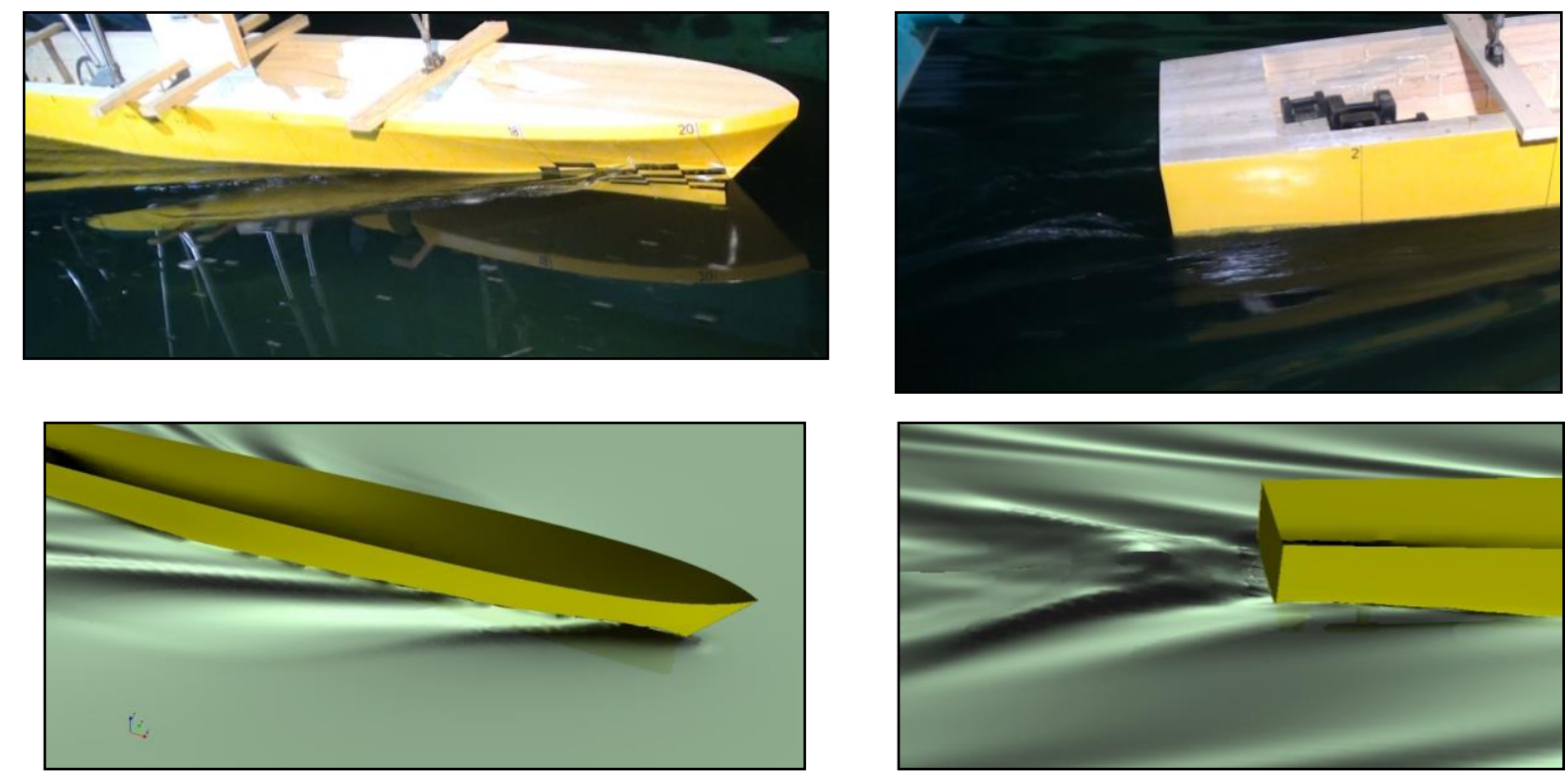

Fig. 14 Bow-wave and stern-wave patterns close-up views for the appended hull for $\mathrm{Fr}=0.215$

\subsection{Wake field}

Wake survey involves a detailed investigation of the flow characteristics through the propeller disc. The wake field greatly depend on ship type. Each ship hull can be considered to have a unique wake field. Nominal wake is obtained based on wake survey carried out by using either experimental or numerical fluid dynamics methods without the presence of propeller. The nominal wake is crucial in propeller design. In this study nominal wake behind the appended hull is investigated. A Pitot tube was used to measure the velocities in the wake field behind the hull. The Pitot tube and experimental setup is given in Figure 15.
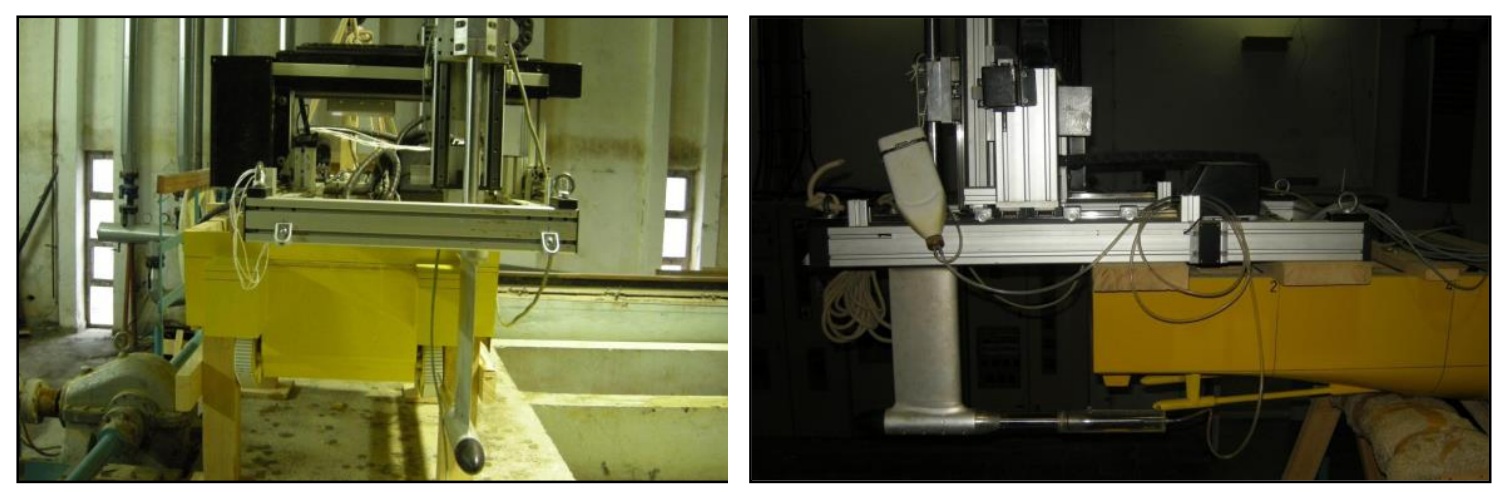

Fig. 15 Pitot tube and wake measurement 


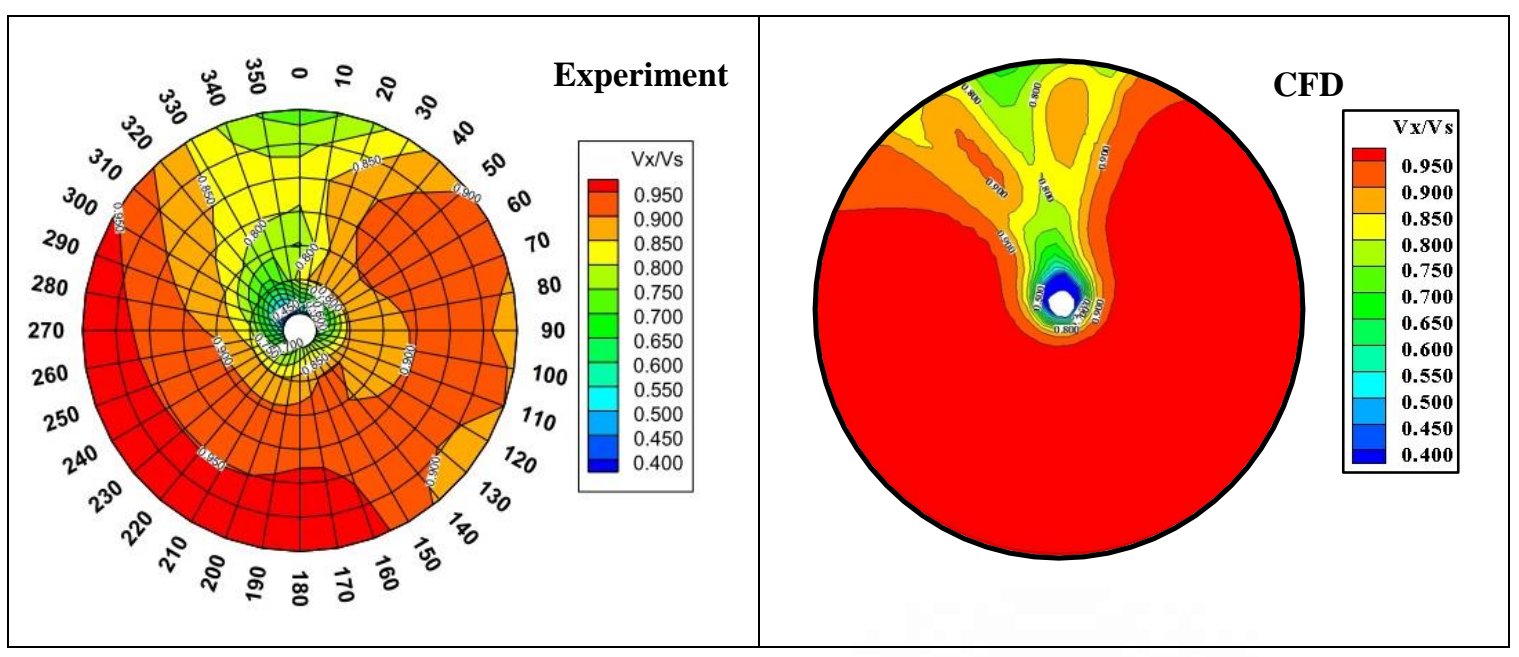

Fig. 16 Comparisons of wake plane

The comparison of the wake plane is depicted in Figure 16. General behavior of the wake distribution seems comparable when matching numerical and experimental results. Although, in some parts of the wake region the values of the computed velocities are greater than the experimental data and the present method does not agree with the experimental results. The authors believe that a more sophisticated turbulence model could solve this issue. When the appendages (propeller shafts and brackets) are taken into account, the computation of the primitive variables near the aft-end part of the hull (especially near the propeller domain) becomes complex. Especially, the helical motion, local separation of the individual appendages, adverse pressure gradient effect and interaction between the devices make the flow structure much more complicated. Figure 17 shows the streamwise velocity contours, similarly, Figure 18 shows the turbulent kinetic energy contours calculated at $\mathrm{Fr}=0.322$. The turbulent kinetic energy (Eq. 4) formed predominantly by the convective terms.
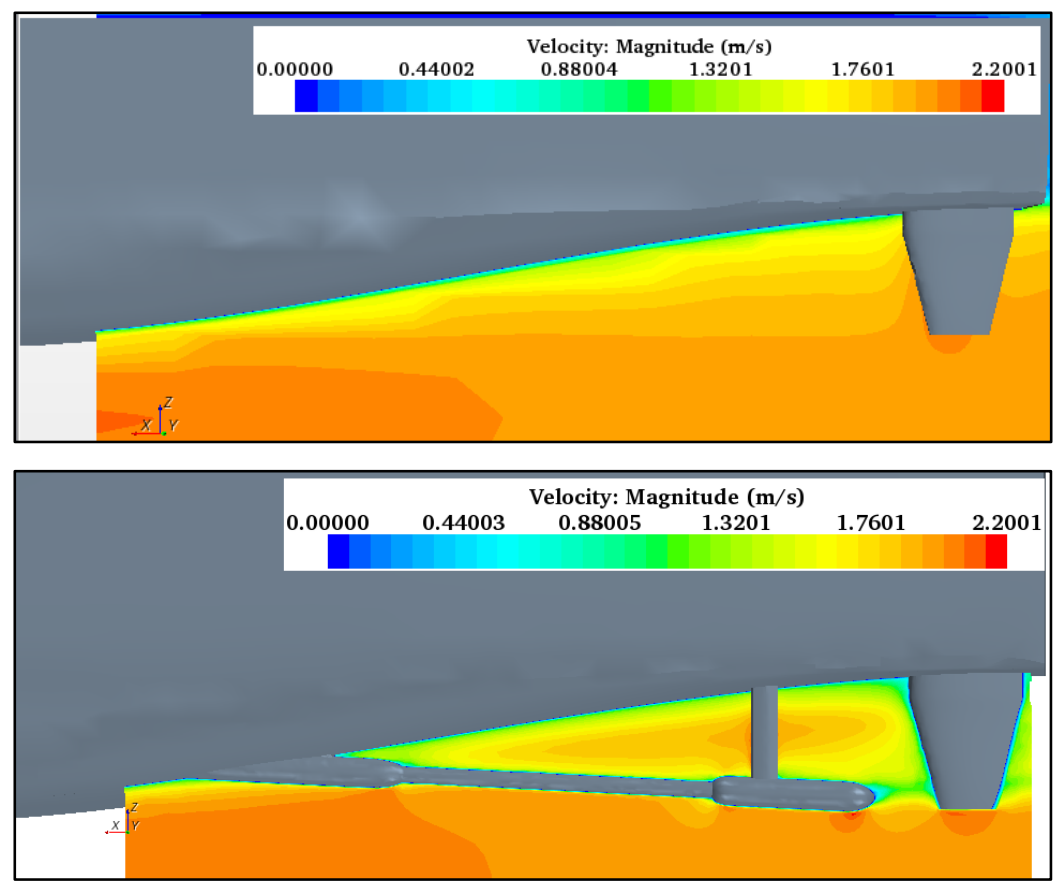

Fig. 17 Streamwise velocity contours of the model with and without appendages $(\mathrm{Fr}=0.322)$ 


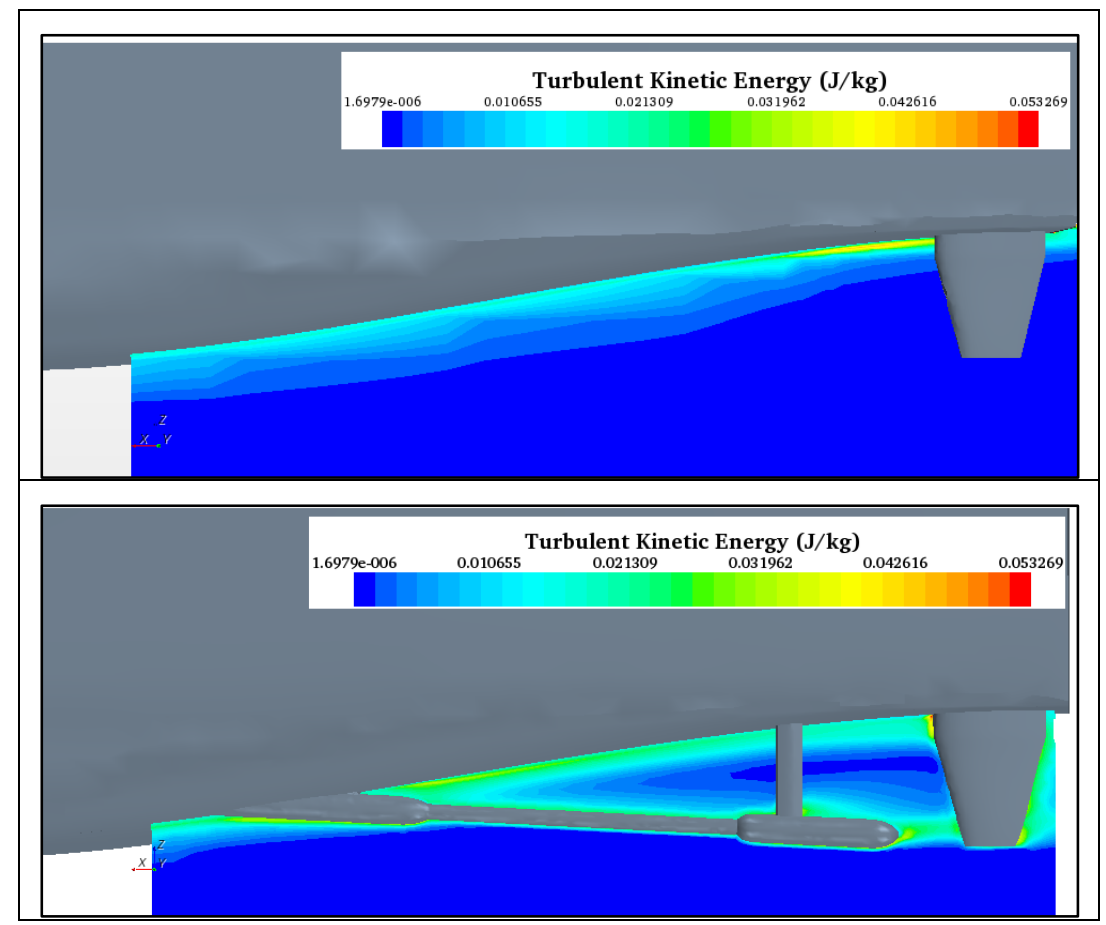

Fig. 18 Turbulent kinetic energy contours of the model with and without appendages $(\mathrm{Fr}=0.322)$

\section{Conclusions}

This paper presents the numerical and experimental results of the flow field around a fast ship model with appendages. Although some experimental data have been showed for validation of CFD results, the main objective of this study is to assess the performance of CFD for design, analysis and feasibility of such a simulation for naval architects and shipping industry. The following conclusions are reached:

- Both experimental and numerical results show that ship resistance increase with appendages.

- As expected, numerical simulation around ship hull with appendages is much more problematic compared to numerical simulation around ship hull without appendages.

- Mesh refinement through adaption is critical, especially near the appendages region to resolve the flow field characteristics.

- The simulated wave pattern around the ship hull is in good agreement with the experimental results.

- The experiments and computations were performed for 11 different Froude numbers between 0.103 and 0.322 . It is suggested that $\mathrm{k}-\varepsilon$ turbulence model may be considered as a useful tool for predicting viscous flows with free surface around an appended ship model for Froude numbers up to 0.25 .

- The effect of the appendages on the ship become more important as the flow velocity increases.

- Appendages increase the total resistance mainly by increasing the pressure resistance, because the total appendages area is insignificant compared to the wetted surface area. 
- The appendages presence caused an acceleration of the flow. Turbulence kinetic energy is getting higher due to the appendages.

Extension of this study is also encouraged in order to examine the effect of different mesh forms and numerical solver methods on the precision of the obtained results. Towing tank test results may be affected by turbulent studs. Using turbulent studs are a standard procedure in towing tank experiments. The surface of the numerical ship model can be considered as a rough surface by using a roughness parameter where the studs are placed. It is also highly recommended to use a more sophisticated turbulence model without using wall functions to well capture the flow properties around the aft-end of the model with appendages. Inherently a suitable low Reynolds number turbulence model is advised for the future work.

\section{REFERENCES}

[1] Xie, N., Vassalos, D., and Sayer, P.: The effect of lift on the wave-making resistance of multi-hull craft. International Shipbuilding Progress, Vol. 54, 2007, pp. 83-95.

[2] Tarafder, Md. S. and Suzuki, K.: Computation of wave-making resistance of a catamaran in deep water using a potential-based panel method. Ocean Engineering, Vol. 34, 2007, pp. 1892-1900. https://doi.org/10.1016/j.oceaneng.2006.06.010

[3] Belibassakis, K.A., Gerostathis, Th.P., Kostas, K.V., Politis, C.G., Kaklis, P.D., Ginnis, A.I. and Feurer, C.: A BEM-isogeometric method for the ship wave-resistance problem. Ocean Engineering, Vol. 60, 2013, pp. 53-57. https://doi.org/10.1016/j.oceaneng.2012.12.030

[4] Kostas, K.V., Ginnis, A.I., Politis, C.G. and Kaklis, P.D.: Ship-hull shape optimization with a T-spline based BEM-isogeometric solver. Comput. Methods Appl. Mech. Engrg., Vol. 284, 2015, pp. 611-622. https://doi.org/10.1016/j.cma.2014.10.030

[5] Anantha Subramarian, V. and Vijayakumar, R.: An inverse design approach for minimizing wake at propeller plane using CFD. Ocean Engineering, Vol. 33, 2006, pp. 119-136. https://doi.org/10.1016/j.oceaneng.2005.04.014

[6] Celik F.: A numerical study for effectiveness of wake equalizing duct. Ocean Engineering, Vol. 34, No:16, 2007, pp. 2138-2145. https://doi.org/10.1016/j.oceaneng.2007.04.006

[7] Kouh, J.S., Chen, Y.J., and Chau, S.W.: Numerical study on scale effect of form factor. Ocean Engineering, Vol. 36, 2009, pp. 403-413. https://doi.org/10.1016/j.oceaneng.2009.01.011

[8] Park, D.W. and Chun, H.H.: Design practice for the stern hull form of a twin-skeg ship. Journal of Marine Science and Technology, Vol. 14, No:3, 2009, pp. 10-32. https://doi.org/10.1007/s00773-009-0046-5

[9] Senocak, I. and Iaccarino, G.: Progress towards RANS simulation of free-surface flow around modern ships. Centre for Turbulence Research Annual Research Briefs, 2005.

[10] Bucan, B., Buca, M.P. and Ruzic, S.: Numerical Modeling of the flow around the Tanker Hull. Brodogradnja, Vol. 59, No:2, 2008, pp. 117-122.

[11] Zwart, P.J., Godin, P.G., Penrose, J. and Rhee, S.H.: Simulation of unsteady free-surface flow around a ship hull using a fully coupled multi-phase flow method. Journal of Marine Science and Technology, Vol. 13, 2008, pp. 346-355. https://doi.org/10.1007/s00773-008-0012-7

[12] Ahmed, Y., Guedes Soares, C.: Simulation of free surface flow around a VLCC hull using viscous and potential flow methods, Ocean Engineering, Vol. 36, No:9, 2009, pp. 691-696. https://doi.org/10.1016/j.oceaneng.2009.03.010

[13] Wackers, J., Koren, B., Raven, H.C., van der Ploeg, A., Starke, A.R., Deng, G.B., Queutey, P., Visonneau, M.: Free-surface viscous flow solution methods for ship hydrodynamics, Arch Comput. Methods Eng., Vol. 18, 2011, pp. 1-41. https://doi.org/10.1007/s11831-011-9059-4

[14] Xing, T., Bhushan, S., Stern, F.: Vortical and turbulent structures for KVLCC2 at drift angle 0, 12, and 30 degrees, Ocean Engineering, Vol. 55, No:5, 2012, pp. 23-43. https://doi.org/10.1016/j.oceaneng.2012.07.026

[15] Sridhar, D., Bhanuprakash, T.V.K., and Das H. N.: Frictional Resistance Calculations on a Ship using CFD. International Journal of Computer Applications, Vol. 11, No:5, 2010, pp. 24-31. https://doi.org/10.5120/1577-2109 
[16] Kandasamy, M., Ooi, S.K., Carrica, P., Stern, F., Campana, E.F., Peri, D., Osborne, P., Cote, J., Macdonald, N. and De Waal, N.: CFD validation studies for a high-speed foil-assisted semi-planning catamaran. Journal of Marine Science and Technology, Vol. 16, No:2, 2011, pp. 157-167. https://doi.org/10.1007/s00773-011-0120-7

[17] Pranzitelli, A., De Nicola, C. and Miranda, S.: Steady state calculations of free surface flow around ship hulls and resistance prediction. Symposium on High Speed Marine Vehicles (HSMV) 2011. Italy.2011

[18] Tezdogan, T., Demirel, Y.K., Kellett, P., Khorasanchi, M., Incecik, A. and Turan, O.: Full-scale unsteady RANS CFD simulations of ship behavior and performance in head seas due to slow steaming. Ocean Engineering, Vol. 97, 2015, pp. 186-206. https://doi.org/10.1016/j.oceaneng.2015.01.011

[19] Ozdemir, Y.H., Cosgun, T., Dogrul, A., and Barlas, B.: A Numerical application to predict the resistance and wave pattern of Kriso Container Ship, Brodogradnja, Vol. 67, No:2, 2016, pp. 47-65. https://doi.org/10.21278/brod67204

[20] Farkas, A., Degiuli, N., and Martic, I.: Numerical simulation of the viscous flow around a tanker model, Brodogradnja, Vol. 68, No:2, 2017, pp. 109-125. https://doi.org/10.21278/brod68208

[21] Szelangiewicz, T. and Abramowski, T.: Numerical analysis of influence of ship hull form modification on ship resistance and propulsion characteristics. Polish Maritime Research, Vol. 16, 2009, pp. 3-8. https://doi.org/10.2478/v10012-008-0049-X

[22] Mahmood, S. and Huang, D.: Computational Fluid Dynamic Based Bulbous Bow Optimization Using a Genetic Algorithm. J. Marine Sci. Appl., Vol. 11, 2012, pp. 286-294. https://doi.org/10.1007/s11804-0121134-1

[23] Duy, T.N., Hino, T. and Kazuo, S.: Numerical study on stern flow fields of ship hulls with different transom configurations. Ocean Engineering, Vol. 129, 2017, pp. 401-414. https://doi.org/10.1016/j.oceaneng.2016.10.052

[24] Muscari, R., Dubbioso, G., Viviani, M., and Mascio, A.D.: Analysis of the asymmetric behavior of propeller-rudder system of twin screw ships by CFD. Ocean Engineering, Vol. 129, 2017, pp. 269-281. https://doi.org/10.1016/j.oceaneng.2017.07.056

[25] Bhushan, S., Mousaviraad, M., and Stern, F.: Assessment of URANS surface effect ship models for calm water and head waves. Applied Ocean Research, Vol. 67, 2017, pp. 248-262. https://doi.org/10.1016/j.apor.2017.07.013

[26] Gaggero, S., Villa, D., and Viviani, M.: An extensive analysis of numerical ship self-propulsion prediction via a coupled BEM/RANS approach. Applied Ocean Research, Vol. 66, 2017, pp. 55-78. https://doi.org/10.1016/j.apor.2017.05.005

[27] Kim, G.H., and Park, S.: Development of a numerical simulation tool for efficient and robust prediction of ship resistance. International Journal of Naval Architecture and Ocean Engineering, Vol. 9, 2017, pp. 537-551. https://doi.org/10.1016/j.ijnaoe.2017.01.003

[28] Ozdemir, Y.H., Barlas B., Yilmaz T., and Bayraktar, S.: Numerical and experimental study of turbulent free surface flow for a fast ship model. Brodogradnja, Vol. 65, No:1, 2014, pp. 39-54.

[29] B. Sener: Developing of frigate type hull form series and hydrodynamic form optimization, Ph.D. Thesis, Yildız Technical University, Istanbul, Turkey, 2012.

[30] Anderson, J.D.: Computational Fluid Dynamics: Basics with Applications, McGraw-Hill International Editions, Singapore, 1995.

[31] Patankar, S.V., Spalding, D.B.: A calculation procedure for heat, mass and momentum transfer in threedimensional parabolic flows, Int. J. Heat Mass Transfer, Vol. 15, No: 10, 2005, pp. 1787-1806.

[32] Star CCM+ Documentation (version 6.06), User's Guide, CD-Adapco, 2011

[33] International Towing Tank Conference (ITTC): Practical guidelines for ship CFD applications. Proceedings of the 26th International Towing Tank Conference, Brazil, 2011

Submitted: $\quad$ 08.12.2017.

Accepted: $\quad 26.03 .2018$.
Yavuz Hakan Ozdemir (e-mail: yhozdemir@comu.edu.tr) Canakkale Onsekiz Mart University, Department of Motor Vehicles and Transportation Technologies, Canakkale, Turkey Baris Barlas (e-mail: barlas@itu.edu.tr) Istanbul Technical University, Department of Naval Architecture and Marine Engineering, Istanbul, Turkey 